\title{
Differences in need for antihypertensive drugs among those aware and unaware of their hypertensive status: a cross sectional survey Nadia A Khan*1, Dennis Wardman ${ }^{2}$ and Norman RC Campbell ${ }^{3}$
}

\author{
Address: ${ }^{1}$ Department of Medicine, University of British Columbia, 620-1081 Burrard Street, St. Paul's Hospital, V6Z 1Y6, Vancouver, BC, Canada, \\ ${ }^{2}$ Department of Health Care and Epidemiology, Health Canada and University of British Columbia, Suite 540 - 757 W. Hastings St. V6C 3E6, \\ Vancouver, BC, Canada and ${ }^{3}$ Department of Medicine, University of Calgary, 3330 Hospital Drive NW, Calgary, AB, T2N 4N1, Canada \\ Email: Nadia A Khan* - nakhan@shaw.ca; Dennis Wardman - dwardman@shaw.ca; Norman RC Campbell - ncampbel@ucalgary.ca \\ * Corresponding author
}

Published: 03 February 2005

BMC Cardiovascular Disorders 2005, 5:4 doi:10.1 |86/147|-226|-5-4

This article is available from: http://www.biomedcentral.com/I47I-226I/5/4

(C) 2005 Khan et al; licensee BioMed Central Ltd.

This is an Open Access article distributed under the terms of the Creative Commons Attribution License (http://creativecommons.org/licenses/by/2.0), which permits unrestricted use, distribution, and reproduction in any medium, provided the original work is properly cited.
Received: 23 September 2004

Accepted: 03 February 2005

\begin{abstract}
Background: Lack of antihypertensive use among hypertensive individuals is a major public health problem. It remains unclear as to how much of this lack of treatment is because of failure to diagnose hypertension or failure to initiate drug treatment for those with a diagnosis of hypertension. The primary aim of this study was to determine the proportion of those untreated individuals who would be recommended to start drug therapy for control of blood pressure among those aware or unaware of their diagnosis of hypertension.
\end{abstract}

Methods: The Canadian Heart Health Surveys (1986 - 1992), a national, cross-sectional descriptive survey $(n=23$ 129), was used to determine the proportion of individuals who were untreated, yet satisfied the 2004 Canadian hypertension guidelines for initiating drug therapy. Patients were divided into subgroups of those aware and unaware of having a diagnosis of hypertension according to self reported awareness from the survey.

Results: Of those with untreated hypertension $(=140 / 90 \mathrm{mmHg})$, only $37 \%$ were aware of their diagnosis. $74 \%$ of untreated individuals aware of their diagnosis of hypertension would require drug therapy, compared to $57 \%$ of those who were unaware. Of those $>65$ years of age, $52 \%$ of aware individuals needed drug therapy whereas only $34 \%$ of unaware elderly would need drug treatment.

Conclusion: In both unaware and aware subgroups, the majority of patients with untreated hypertension would benefit from antihypertensive drug therapy according to the 2004 Canadian Hypertension recommendations. The proportion of untreated patients that still need drug therapy was higher among those who were aware compared to those who were unaware. This finding suggests that the major gap in hypertension control may be in initiating drug therapy rather than in diagnosing hypertension. Further studies are needed to confirm these results to ultimately help strategize public health efforts in controlling hypertension.

\section{Background}

Antihypertensive drug therapy can reduce cardiovascular morbidity and mortality by $25-30 \%$ [1-3] in those with hypertension. The 2004 Canadian hypertension guide- lines [4] recommend pharmacotherapy in those patients where there is proven cardiovascular benefit from randomized controlled trial evidence. However, many of these 'at risk' patients with hypertension remain untreated even 
Table I: Proportions of those aware and unaware who require drug therapy $(95 \% \mathrm{Cl})$

\begin{tabular}{cccc}
\hline Awareness of hypertensive status & $>65$ years & $18-64$ years & Total \\
Aware & $71477 / 138342$ & 592 186/ 759 444 & $663663 / 897786$ \\
Unaware & $51.7 \%(51.5-51.9 \%)$ & $78 \%(77.9-78.1 \%)$ & $73.9 \%(73.8-74 \%)$ \\
& $129398 / 376861$ & $738542 / 1143872$ & $867940 / 1520733$ \\
$57.1 \%(57-57.2 \%)$ \\
\hline
\end{tabular}

though they have a higher risk for cardiovascular events [5]. This lack of treatment is a major public health problem as hypertension is a modifiable risk factor. It remains unclear as to how much of this lack of treatment is because of failure to diagnose hypertension or failure to initiate drug treatment for those with a diagnosis of hypertension. Further understanding would help to strategize public health care initiatives in controlling high blood pressure. The primary aim of this study was to determine the proportion of those untreated individuals who would be recommended to start drug therapy for control of blood pressure among those aware or unaware of their diagnosis of hypertension.

\section{Methods}

From the 2004 Canadian Hypertension Guidelines, pharmacotherapy is recommended if the diastolic blood pressure is > $100 \mathrm{mmHg}$; the systolic pressure is > $160 \mathrm{mmHg}$; or the diastolic blood pressure is $>90 \mathrm{mmHg}$ in the presence of cardiovascular heart disease or risk factors. To determine the proportions of individuals who satisfied the guidelines for initiation of drug treatment for hypertension, we used the Canadian Heart Health Surveys (1986 - 1992). This national, cross-sectional descriptive survey $(\mathrm{n}=23129)$ contains data on individual blood pressure measurements using standardized technique as well as information on cardiovascular risk profile, antihypertensive medication use and self reported awareness of hypertension. Further details of this survey have been published elsewhere [6]. We then calculated for both aware and unaware subgroups, the number of untreated hypertensive individuals that would be recommended drug therapy/ those untreated, hypertensive individuals. Patients with diabetes mellitus were excluded from the analysis because they require antihypertensive drug therapy at a much lower threshold. Descriptive statistics were used to calculate proportions and 95\% confidence intervals in this study.

\section{Results}

Of those with untreated hypertension $(=140 / 90 \mathrm{mmHg})$, only $37 \%(n=897786)$ were aware of their diagnosis. Among those aware and unaware of their diagnosis of hypertension, $35 \%$ vs. $36 \%$ were female; $14 \%$ vs. $12 \%$ had any cardiovascular disease and $31 \%$ vs. $75 \%$ were under the age of 65 years respectively. The proportions of those who would be recommended drug therapy among those who are aware and unaware are presented in Table 1 . Table 1 demonstrates that compared to the unaware subgroup, a greater proportion of those aware of their hypertensive status needed drug therapy but were untreated. Among both aware and unaware groups, the largest proportion needing drug therapy was less than age 65 years. Of note, among those who were unaware, there was a considerably lower proportion that needed drug therapy over the age of 65 years.

\section{Discussion}

In both unaware and aware subgroups, the majority of patients with untreated hypertension would benefit from antihypertensive drug therapy according to the 2004 Canadian Hypertension recommendations. This analysis extends the findings from other studies $[5,7,8]$ by determining those 'at risk' individuals that would be recommended pharmacotherapy based on awareness of their hypertensive status. The proportion of untreated patients that still needed drug therapy was higher among those who were aware compared to those who were unaware. Specifically, among the elderly, most of the patients who are unaware that they are hypertensive would not actually be recommended to take drug therapy. These study findings suggest that a significant gap in hypertension control may be initiating drug therapy among those known to have hypertension. Possible barriers to initiating drug therapy may arise from patients, physicians [9] or the health care system.

There are several limitations with this study. First, the Canadian Heart Health Survey data are 12 years old and there is some evidence to suggest that prescription rates of antihypertensive drugs have improved since then [10]. However, this data set represents the best population data available on patients with hypertension in Canada since it is of high quality and captures a large cohort of Canadians. Another limitation is that the awareness or unawareness of hypertensive status is based on self report and not from physician records. 


\section{Conclusion}

This study found a considerable number of both unaware and aware patients with untreated hypertension require drug therapy. However, the majority of those who needed drug therapy were actually aware that they had a diagnosis of hypertension compared to those who were not aware. This finding suggests that the major gap in hypertension control may be in initiating drug therapy rather than in diagnosing hypertension. Further studies are needed to confirm these results to ultimately help strategize public health efforts in controlling hypertension.

\section{Competing interests}

The author(s) declare that they have no competing interests.

\section{Authors' Contribution}

NK, DW and NC contributed to the design of the project. NK contributed to data analysis. NK, DW and NC contributed to writing the manuscript and for substantive, intellectual editing contributions.

\section{Acknowledgements}

Dr. Khan is supported by Canadian Institute Health Research and Michael Smith Foundation for Health Research postdoctoral fellowship awards. The authors would also like to thank Vicki Stagg for her biostatistical support.

\section{References}

I. MacMahon S, Peto R, Cutler J, Collins R, Sorlie P, Neaton J, Abbott R, Godwin J, Dyer A, Stamler J: Blood pressure, stroke, and coronary heart disease. Part I, Prolonged differences in blood pressure: prospective observational studies corrected for the regression dilution bias. Lancet 1990, 335:765-74.

2. Gueyffier F, Boutitie F, Boissel JP, Pocock S, Coope J, Cutler J, Ekbom $T$, Fagard R, Friedman L, Perry M, Prineas R, Schron E: Effect of antihypertensive drug treatment on cardiovascular outcomes in women and men. A meta-analysis of individual patient data from randomized, controlled trials. The INDANA Investigators. Ann Intern Med 1997, I 26:76I-7.

3. Collins R, Peto R, MacMahon S, Hebert P, Fiebach NH, Eberlein KA, Godwin J, Qizilbash N, Taylor JO, Hennekens CH: Blood pressure, stroke, and coronary heart disease. Part 2, Short-term reductions in blood pressure: overview of randomized drug trials in their epidemiological context. Lancet 1990, 335:827-38.

4. Khan NA, McAlister FA, Campbell NR, Feldman RD, Rabkin S, Mahon J, Lewanczuk R, Zarnke KB, Hemmelgarn B, Lebel M, Levine M, Herbert C, Canadian Hypertension Education Program: The 2004 Canadian recommendations for the management of hypertension: Part II - Therapy. Can J Cardiol 2004, 20(I):4 I-54.

5. Khan N, Chockalingam A, Campbell NR: Lack of control of high blood pressure and treatment recommendations in Canada. Can J Cardiol 2002, I 8(6):657-61.

6. MacLean DR, Petrasovits A, Nargundkar M, Connelly PW, MacLeod E, Edwards A, Hessel P: Canadian heart health surveys: a profile of cardiovascular risk. Survey methods and data analysis. Canadian Heart Health Surveys Research Group. CMAJ 1992, I 46(I I): 1969-74.

7. Joffres MR, Hamet P, Rabkin SW, Gelskey D, Hogan K, Fodor G: Prevalence, control and awareness of high blood pressure among Canadian adults. Canadian Heart Health Surveys Research Group. CMAJ 1992, I 46( I I): 1997-2005.

8. Joffres MR, Ghadirian P, Fodor JG, Petrasovits A, Chockalingam A, Hamet $P$ : Awareness, treatment, and control of hypertension in Canada. Am J Hypertens 1997, I0 (IO Pt I): 1097- 102.

9. Oliveria SA, Lapuerta P, McCarthy BD, L'Italien GJ, Berlowitz DR, Asch SM: Physician-related barriers to the effective manage- ment of uncontrolled hypertension. Arch Intern Med 2002, 162(4):413-20.

10. Campbell NRC, McAlister F, Brant R, Levine M, Drouin D, Feldman R, Herman R, Zarnke K, for the Canadian Hypertension Education Process and Evaluation Committee: Temporal trends in antihypertensive drug prescriptions in Canada before and after introduction of the Canadian Hypertension Education Program. J Hypertens 2003, 21(8): 1591-7.

\section{Pre-publication history}

The pre-publication history for this paper can be accessed here:

http://www.biomedcentral.com/1471-2261/5/4/prepub
Publish with Bio Med Central and every scientist can read your work free of charge

"BioMed Central will be the most significant development for disseminating the results of biomedical research in our lifetime. " Sir Paul Nurse, Cancer Research UK

Your research papers will be:

- available free of charge to the entire biomedical community

- peer reviewed and published immediately upon acceptance

- cited in PubMed and archived on PubMed Central

- yours - you keep the copyright

Submit your manuscript here:

http://www.biomedcentral.com/info/publishing_adv.asp
BioMedcentral 